\title{
A Multicenter Study to Identify the Respiratory Pathogens Associated with Exacerbation of Chronic Obstructive Pulmonary Disease in Korea
}

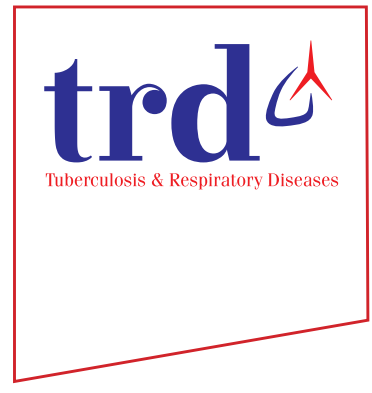

Hyun Woo Lee, M.D. ${ }^{1}{ }^{(\mathbb{D}}$, Yun Su Sim, M.D., Ph.D. ${ }^{2}$, Ji Ye Jung, M.D., Ph.D. ${ }^{3}$, Hyewon Seo, M.D. ${ }^{4}$, Jeong-Woong Park, M.D., Ph.D. ${ }^{5}$, Kyung Hoon Min, M.D., Ph.D. ${ }^{6}$, Jae Ha Lee, M.D., Ph.D. ${ }^{7}$, ByungKeun Kim, M.D., Ph.D. ${ }^{8}$, Myung Goo Lee, M.D., Ph.D. ${ }^{9}$, Yeon-Mok Oh, M.D., Ph.D. ${ }^{10}$, Seung Won Ra, M.D., Ph.D. ${ }^{11}$, Tae-Hyung Kim, M.D., Ph.D. ${ }^{12}$, Yong Il Hwang, M.D., Ph.D. ${ }^{13}$, Chin Kook Rhee, M.D., Ph.D. ${ }^{14}$, Hyonsoo Joo, M.D., Ph.D. ${ }^{15}$, Eung Gu Lee, M.D. ${ }^{16}$, Jin Hwa Lee, M.D., Ph.D. ${ }^{17}$, Hye Yun Park, M.D., Ph.D. ${ }^{18}$, Woo Jin Kim, M.D., Ph.D. ${ }^{19}$, Soo-Jung Um, M.D., Ph.D. ${ }^{20}$, Joon Young Choi, M.D., Ph.D. ${ }^{21}$, Chang-Hoon Lee, M.D., Ph.D. ${ }^{22}$, Tai Joon An, M.D. ${ }^{23}$, Yeonhee Park, M.D. ${ }^{24}$, YoungSoon Yoon, M.D. ${ }^{25}$, Joo Hun Park, M.D., Ph.D. ${ }^{26}$, Kwang Ha Yoo, M.D., Ph.D. ${ }^{27}$ (iD and Deog Kyeom Kim, M.D., Ph.D. ${ }^{1}$ (i)

*Author affiliations appear at the end of this article.

Background: Although respiratory tract infection is one of the most important factors triggering acute exacerbation of chronic obstructive pulmonary disease (AE-COPD), limited data are available to suggest an epidemiologic pattern of microbiology in South Korea.

Methods: A multicenter observational study was conducted between January 2015 and December 2018 across 28 hospitals in South Korea. Adult patients with moderate-to-severe acute exacerbations of COPD were eligible to participate in the present study. The participants underwent all conventional tests to identify etiology of microbial pathogenesis. The primary outcome was the percentage of different microbiological pathogens causing AE-COPD. A comparative microbiological analysis of the patients with overlapping asthma-COPD (ACO) and pure COPD was performed.

Results: We included 1,186 patients with AE-COPD. Patients with pure COPD constituted $87.9 \%$ and those with ACO accounted for $12.1 \%$. Nearly half of the patients used an inhaled corticosteroid-containing regimen and one-fifth used systemic corticosteroids. Respiratory pathogens were found in $55.3 \%$ of all such patients. Bacteria and viruses were

Address for correspondence: Kwang Ha Yoo, M.D., Ph.D.

Department of Internal Medicine, Konkuk University Hospital, 120-1 Neungdong-ro, Gwangjin-gu, Seoul 05030, Republic of Korea

Phone: 82-2-2030-7522, Fax: 82-2-2030-7458, E-mail: khyou@kuh.ac.kr

Address for correspondence: Deog Kyeom Kim, M.D., Ph.D.

Division of Respiratory and Critical Care, Department of Internal Medicine, Seoul Metropolitan Government-Seoul National University Boramae Medical Center, 20 Boramae-ro-5-gil, Dongjak-gu, Seoul 07061, Republic of Korea

Phone: 82-2-870-2228, Fax: 82-2-870-7378, E-mail: kimdkmd@snu.ac.kr

Received: May. 14, 2021, Revised: Jul. 23, 2021, Accepted: Oct. 16, 2021, Published online: Oct. 20, 2021

@(t) is identical to the Creative Commons Attribution Non-Commercial License (http://creativecommons.org/licenses/by-nc/4.0/). 
detected in $33 \%$ and $33.2 \%$, respectively. Bacterial and viral coinfections were found in $10.9 \%$. The most frequently detected bacteria were Pseudomonas aeruginosa (9.8\%), and the most frequently detected virus was influenza A (10.4\%). Multiple bacterial infections were more likely to appear in ACO than in pure COPD (8.3\% vs. 3.6\%, $\mathrm{p}=0.016)$.

Conclusion: Distinct microbiological patterns were identified in patients with moderate-to-severe AE-COPD in South Korea. These findings may improve evidence-based management of patients with AE-COPD and represent the basis for further studies investigating infectious pathogens in patients with COPD.

Keywords: Symptom Flare Up; Pulmonary Disease, Chronic Obstructive; Microbiology; Bacteriology; Virology

\section{Introduction}

Chronic obstructive pulmonary disease (COPD) is an important disease associated with inhalation of toxic chemicals, with increased risk of morbidity and mortality worldwide $\mathrm{e}^{1-3}$. Acute exacerbation of COPD (AE-COPD) is associated with prolonged hospitalization and higher mortality rate rest $^{4,5}$. Most cases of AE-COPD are triggered by respiratory tract infections, especially bacteria or viruses ${ }^{6,7}$. A prospective cohort study identified infectious etiologies in $88 \%$ of patients with $\mathrm{AE}-\mathrm{COPD}^{8}$. Several studies have shown a significantly increased bacterial burden during exacerbations using invasive procedures such as bronchoscopic sampling with protected specimen brushing ${ }^{9,10}$. During AE-COPD, the host immune system may not be able to eliminate microorganisms from the lower airways easily due to impaired phagocytic function of macrophages and neutrophils ${ }^{11}$. Therefore, an appropriate choice of antibiotic agent is required to reduce treatment failure or mortality ${ }^{12,13}$. As antibiotic agents are selected based on the local microbiologic spectrum, it is important to investigate the epidemiologic pattern of bacterial and viral pathogens in patients with AE-COPD.

Several studies have already performed etiological analysis of bacteria and viruses in patients with AE-COPD. Using conventional sputum culture, bacterial pathogens were detected in approximately $30 \%-50 \%$ of patients with AE-COPD ${ }^{14,15}$. Other studies reported that viruses caused approximately $34 \%$ of AE-COPD events ${ }^{8,16}$. However, the epidemiological distribution of respiratory pathogens varied in each study region. The clinical management of patients with AE-COPD in South Korea is limited by the lack of microbial epidemiologic data. Therefore, we conducted a nationwide study to identify the distribution patterns of respiratory pathogens in South Korean patients diagnosed with AE-COPD.

\section{Materials and Methods}

This study is in accordance with the guidance of strengthening the reporting of observational studies in epidemiology
(STROBE) statement ${ }^{17}$.

\section{Study design, setting, and participants}

The present multicenter observational study was based on the electronic medical records of patients diagnosed with AE-COPD at 28 hospitals in South Korea between January 2015 and December 2018. The eligibility criteria for the present study were as follows: (1) aged $>40$ years, (2) history of COPD diagnosed with compatible lung function test results (post-bronchodilator forced expiratory volume in 1 second $\left[\mathrm{FEV}_{1}\right] /$ forced vital capacity $<0.7$ ) within the past 6 months), (3) diagnosis of moderate-to-severe AE-COPD, and (4) evaluation with all conventional tests for pathogen identification to identify the causative agent in COPD exacerbations. The diagnosis of moderate-to-severe AE-COPD was determined by the attending physician based on the definition of the Global Initiative for Obstructive Lung Disease (GOLD) guidelines: an acute condition with worsening of respiratory symptoms such as cough, dyspnea, wheezing, and chest discomfort, which leads to treatment with antibiotics, systemic corticosteroids, or hospitalization $^{18}$. We classified patients with asthma-COPD overlap (ACO) as a distinct phenotype of COPD and analyzed them separately ${ }^{19,20}$. ACO was defined as the coexistence of asthma and COPD in patients with chronic airway obstruc$\operatorname{tion}^{21}$. The diagnosis of asthma and COPD was based on the GOLD and the Global Initiative for Asthma report, respectively.

\section{Variables}

All variables were ascertained from the electronic medical records of each hospital. Demographic data included patient's age, sex, body mass index, disease duration, treatment duration, smoking history, pack-year, pneumococcal vaccination history, other respiratory disease history, and underlying comorbidities. Regarding history of other respiratory diseases, a history of tuberculosis, bronchiectasis, interstitial lung disease, chronic bronchitis, pneumonia, and sinusitis was found. We searched the medical records of patients with diabetes mel- 
litus, hypertension, liver cirrhosis, congestive heart failure, chronic kidney disease, cerebrovascular disease, and advanced cancer.

Clinical data included serum eosinophilia, lung function parameters $\left(\mathrm{FEV}_{1}\right.$, bronchodilator response, fractional exhaled nitric oxide [FeNO]), disease severity (COPD assessment test [CAT], modified Medical Research Council [mMRC], and annual exacerbation rate), GOLD group, and prescribed inhaled or oral medications. Eosinophilia was defined by an eosinophil count $>5 \%$ in the blood test within 6 months before the event of acute exacerbation of COPD. Inhaled treatments included short-acting beta-agonists, long-acting beta-agonists (LABA), long-acting muscarinic antagonists (LAMA), inhaled corticosteroids (ICS), and their combinations. Oral medications included leukotriene receptor antagonists, systemic corticosteroids, and xanthine derivatives.

Microbiological data were obtained from the results of all available bacterial and viral tests including sputum culture studies; sputum bacterial polymerase chain reaction (PCR) tests for Mycoplasma pneumoniae, Chlamydophila pneumoniae, Legionella pneumophila, and Bordetella pertussis; serum antibody tests for $M$. pneumoniae and C. pneumoniae; sputum virus PCR tests; and nasal swab tests for influenza A and $\mathrm{B}$ virus antigens. We subdivided the included patients into six groups based on pathogen classification according to microbiological test results: (1) no pathogen detected; (2) single

Table 1. Baseline demographic and clinical characteristics of patients with acute exacerbation of chronic respiratory disease

\begin{tabular}{|c|c|c|c|c|}
\hline & Total $(n=1,186)$ & $\operatorname{ACO}(n=144)$ & $\operatorname{COPD}(n=1,042)$ & p-value \\
\hline Age, yr & $73.78 \pm 9.22$ & $74.85 \pm 8.91$ & $73.63 \pm 9.26$ & 0.137 \\
\hline Female sex & $207(17.5)$ & $42(29.2)$ & $165(15.8)$ & $<0.001$ \\
\hline BMI & $21.53 \pm 3.98$ & $21.99 \pm 3.91$ & $21.46 \pm 3.99$ & 0.164 \\
\hline $\mathrm{BMI}>25 \mathrm{~kg} / \mathrm{m}^{2}$ & $181(17.7)$ & $24(19.0)$ & $157(17.5)$ & 0.772 \\
\hline Disease duration, yr & $7.60 \pm 6.60$ & $9.28 \pm 6.94$ & $7.36 \pm 6.52$ & 0.001 \\
\hline Treatment duration, yr & $6.98 \pm 6.48$ & $8.18 \pm 6.29$ & $6.82 \pm 6.49$ & 0.019 \\
\hline Smoking history & & & & 0.675 \\
\hline Never smoker & $313(27.1)$ & $43(29.9)$ & $270(26.7)$ & \\
\hline Current smoker & $156(13.5)$ & $20(13.9)$ & $136(13.4)$ & \\
\hline Ex-smoker & $688(59.5)$ & $81(56.2)$ & $607(59.9)$ & \\
\hline Pack-year & $27.24 \pm 28.10$ & $29.28 \pm 34.46$ & $26.96 \pm 27.12$ & 0.353 \\
\hline Pneumococcal vaccination history & $261(22.0)$ & $27(18.8)$ & $234(22.5)$ & 0.366 \\
\hline \multicolumn{5}{|l|}{ Previous respiratory disease } \\
\hline Tuberculosis & $377(31.8)$ & $41(28.5)$ & $336(32.2)$ & 0.414 \\
\hline Bronchiectasis & $169(14.2)$ & $17(11.8)$ & $152(14.6)$ & 0.443 \\
\hline Interstitial lung disease & $27(2.3)$ & $1(0.7)$ & $26(2.5)$ & 0.289 \\
\hline Chronic bronchitis & $192(16.2)$ & $43(29.9)$ & $149(14.3)$ & $<0.001$ \\
\hline Pneumonia & $615(51.9)$ & $75(52.1)$ & $540(51.8)$ & $>0.99$ \\
\hline Sinusitis & $44(3.7)$ & $5(3.5)$ & $39(3.7)$ & $>0.99$ \\
\hline \multicolumn{5}{|l|}{ Comorbidities } \\
\hline Diabetes mellitus & $318(26.8)$ & $40(27.8)$ & $278(26.7)$ & 0.858 \\
\hline Hypertension & $584(49.2)$ & $78(54.2)$ & $506(48.6)$ & 0.241 \\
\hline Liver cirrhosis & $23(1.9)$ & $6(4.2)$ & $17(1.6)$ & 0.081 \\
\hline Congestive heart failure & $166(14.0)$ & $17(11.8)$ & $149(14.3)$ & 0.496 \\
\hline Chronic kidney disease & $76(6.4)$ & $8(5.6)$ & $68(6.5)$ & 0.792 \\
\hline Cerebrovascular disease & $70(5.9)$ & $3(2.1)$ & $67(6.4)$ & 0.059 \\
\hline Advanced cancer & $138(11.6)$ & $16(11.1)$ & $122(11.7)$ & 0.944 \\
\hline
\end{tabular}

Values are presented as the mean \pm standard deviation or number (\%).

ACO: asthma-COPD overlap; COPD: chronic obstructive pulmonary disease; BMI: body mass index. 
bacterial infection; (3) multiple bacterial infection; (4) single viral infection; (5) multiple viral infection; and (6) bacterial and viral coinfection.

\section{Study outcomes}

The primary outcome was to identify different microbiologi-

Table 2. Clinical parameters and pharmacologic management of patients with COPD

\begin{tabular}{|c|c|c|c|c|}
\hline & Total $(n=1,186)$ & $\operatorname{ACO}(n=144)$ & COPD $(n=1,042)$ & p-value \\
\hline Serum eosinophilia* & $108(9.1)$ & $17(11.8)$ & $91(8.7)$ & 0.295 \\
\hline \multicolumn{5}{|l|}{ Lung function } \\
\hline $\mathrm{FEV}_{1}, \mathrm{~L}$ & $1.19 \pm 0.54$ & $1.18 \pm 0.53$ & $1.20 \pm 0.54$ & 0.804 \\
\hline $\mathrm{FEV}_{1}, \%$ & $49.46 \pm 21.08$ & $50.29 \pm 18.62$ & $49.32 \pm 21.46$ & 0.631 \\
\hline Bronchodilator response positivity & $168(14.4)$ & $55(38.5)$ & $113(11.0)$ & $<0.001$ \\
\hline Fractional exhaled nitric oxide & $9.88 \pm 16.74$ & $29.07 \pm 25.66$ & $8.31 \pm 14.83$ & $<0.001$ \\
\hline \multicolumn{5}{|l|}{ Disease severity } \\
\hline \multicolumn{5}{|l|}{ Baseline condition in $\mathrm{COPD}^{\dagger}$} \\
\hline COPD assessment test & $22.52 \pm 9.81$ & $23.21 \pm 5.65$ & $22.28 \pm 10.88$ & 0.597 \\
\hline Modified medical research council & $2.25 \pm 0.88$ & $2.51 \pm 0.87$ & $2.21 \pm 0.88$ & 0.014 \\
\hline Moderate exacerbation per year & $0.59 \pm 1.27$ & $1.01 \pm 1.22$ & $0.53 \pm 1.26$ & $<0.001$ \\
\hline Severe exacerbation per year & $0.97 \pm 1.29$ & $1.24 \pm 1.24$ & $0.93 \pm 1.29$ & 0.008 \\
\hline \multicolumn{5}{|l|}{ GOLD group } \\
\hline A & $63(5.3)$ & $4(2.8)$ & $59(5.7)$ & 0.212 \\
\hline B & $140(11.8)$ & $10(6.9)$ & $130(12.5)$ & 0.073 \\
\hline $\mathrm{C}$ & $40(3.4)$ & $6(4.2)$ & $34(3.3)$ & 0.751 \\
\hline $\mathrm{D}$ & $224(18.9)$ & $49(34.0)$ & $175(16.8)$ & $<0.001$ \\
\hline Unknown & $719(60.6)$ & $75(52.1)$ & $644(61.8)$ & 0.032 \\
\hline \multicolumn{5}{|l|}{ Inhaled treatment } \\
\hline SABA & $392(33.1)$ & $47(32.6)$ & $345(33.2)$ & 0.974 \\
\hline LABA & $41(3.5)$ & $10(6.9)$ & $31(3.0)$ & 0.028 \\
\hline LAMA & $172(14.5)$ & $26(18.1)$ & $146(14.0)$ & 0.244 \\
\hline LAMA/LABA & $193(16.3)$ & $12(8.3)$ & $181(17.4)$ & 0.008 \\
\hline ICS-containing regimens & $565(47.6)$ & $115(79.9)$ & $450(43.2)$ & $<0.001$ \\
\hline ICS & $36(3.0)$ & $17(11.8)$ & $19(1.8)$ & $<0.001$ \\
\hline ICS/LABA & $185(15.6)$ & $55(38.2)$ & $130(12.5)$ & $<0.001$ \\
\hline ICS/LAMA/LABA & $355(29.9)$ & $48(33.3)$ & $307(29.5)$ & 0.393 \\
\hline No inhaler & $264(22.3)$ & $9(6.2)$ & $255(24.5)$ & $<0.001$ \\
\hline \multicolumn{5}{|l|}{ Oral medication } \\
\hline Leukotriene receptor antagonist & $216(18.2)$ & $76(52.8)$ & $140(13.5)$ & $<0.001$ \\
\hline Systemic corticosteroid & $238(20.1)$ & $41(28.5)$ & $197(18.9)$ & 0.010 \\
\hline Xanthine derivative & $365(30.9)$ & $47(32.6)$ & $318(30.6)$ & 0.690 \\
\hline
\end{tabular}

Values are presented as number (\%) or mean \pm standard deviation unless otherwise indicated.

*Serum eosinophilia was defined as an eosinophil count $>5 \%$ in the blood test within 6 months before the event of acute exacerbation of COPD. 'Data involving COPD assessment test score or modified Medical Research Council score were available for 477 patients. Data related to exacerbation history were available for 1,008 patients.

COPD: chronic obstructive pulmonary disease; ACO: asthma-COPD overlap; $\mathrm{FEV}_{1}$ : forced expiratory volume in one second; GOLD: Global Initiative for Obstructive Lung Disease; SABA: short-acting beta-agonist; LABA: long-acting beta-agonist; LAMA: long-acting muscarinic antagonist; ICS: inhaled corticosteroid. 
cal pathogens causing AE-COPD. Microbiologic pathogens were evaluated at the individual bacterial or viral species and pathogen class levels.

\section{Statistical methods}

Descriptive analyses were used for baseline characteristics and clinical features of the participants. Categorical variables are summarized as percentages, while continuous variables are summarized as means and standard deviations. For comparative analyses, we used Pearson's chi-square test or Fisher's exact test for categorical variables and Student's t-test for continuous variables. Statistical significance was set at $p<0.05$. All analyses were performed using R software: a language and environment for statistical computing, version 3.6.1 (R Core Team [2019], Vienna, Austria).

\section{Ethics}

The study protocol was approved by the Institutional Review Board Committee of each hospital (Seoul National University Seoul Metropolitan Government (SNU-SMG) Boramae Medical Center IRB No. 30-2019-109). All the patients in the current study provided written informed consent for participation.

\section{Results}

We evaluated 1,186 patients with AE-COPD, including 1,042 (87.9\%) met the criteria for pure COPD and 144 (12.1\%) met the criteria for ACO.

\section{Baseline characteristics}

The mean age of the patients with AE-COPD was 74 years, and approximately $82.5 \%$ of them were male (Table 1 ). The mean duration of COPD was 7.6 years, and the mean duration for COPD treatment was 7.0 years. Among the patients, $13.5 \%$ were currently smokers and $78.0 \%$ were not vaccinated for pneumococcus. We found that some patients had experienced infectious respiratory disease before the current AECOPD event: pneumonia (51.9\%) and tuberculosis (31.8\%). Bronchiectasis and interstitial lung disease were found in $14.2 \%$ and $2.3 \%$ of patients, respectively. We found at least one comorbid disease in $68.1 \%$ of the patients. Patients diagnosed with ACO were mostly female, had a longer disease or treatment duration, and a higher rate of chronic bronchitis compared with patients without ACO.

\section{Clinical features}

The patients' baseline clinical features before the AE-COPD event were evaluated (Table 2). Serum eosinophilia $(>\mathbf{5 \%})$ within the past 6 months was detected in $9.1 \%$ of the patients. The mean value of $\mathrm{FEV}_{1}$ was $1.19 \mathrm{~L}$ (49.5\%). The bronchodilator response was identified in $14 \%$ of the patients. The mean FeNO level was $10 \mathrm{ppb}$. In the evaluation of COPD severity, the mean CAT score was 22.5 and the mean mMRC score was 2.25. The rates of moderate and severe exacerbation were $0.59 \%$ and $0.97 \%$ per year, respectively. Among the total of patients, 467 (39.4\%) with the information on symptom scores (CAT or mMRC) and a history of exacerbation were classified into GOLD groups. Based on GOLD group classification, approximately $80 \%$ had a history of exacerbation: 140 patients $(30.0 \%)$ in group B and 224 patients $(48.0 \%)$ in group D. Among patients without a history of exacerbation, 63 (13.5\%) were classified into group A and 40 (8.6\%) into group C. Patients diagnosed with ACO showed a higher positivity rate of bronchodilator response, a higher level of FeNO, a higher mMRC score, a higher rate of moderate and severe exacerbation, and constituted a higher proportion of GOLD D.

Table 3. Classification of respiratory pathogens in patients with acute exacerbation of chronic obstructive pulmonary disease

\begin{tabular}{|c|c|c|c|c|}
\hline & Total $(n=1,186)$ & $\operatorname{ACO}(n=144)$ & $\operatorname{COPD}(n=1,042)$ & p-value \\
\hline \multicolumn{5}{|l|}{ Bacterial class } \\
\hline No bacteria detected & $805(67.9)$ & $91(63.2)$ & $714(68.5)$ & 0.235 \\
\hline Single bacteria detected & 343 (28.9) & $43(29.9)$ & $300(28.8)$ & 0.867 \\
\hline Multiple bacteria detected & $38(3.2)$ & $10(6.9)$ & $28(2.7)$ & 0.014 \\
\hline \multicolumn{5}{|l|}{ Virus class } \\
\hline No virus detected & $792(66.8)$ & $88(61.1)$ & $704(67.6)$ & 0.148 \\
\hline Single virus detected & $361(30.4)$ & $50(34.7)$ & $311(29.8)$ & 0.273 \\
\hline Multiple virus detected & $33(2.8)$ & $6(4.2)$ & $27(2.6)$ & 0.420 \\
\hline
\end{tabular}

Values are presented as number (\%).

ACO: asthma-COPD overlap; COPD: chronic obstructive pulmonary disease. 
Inhaled pharmacological treatment for stable COPD was prescribed for $77.7 \%$ of the included patients (Table 2). ICScontaining regimens including ICS, ICS/LABA, and ICS/ LABA/LAMA were prescribed to $47.6 \%$ of patients. The most commonly used inhaler was ICS/LABA/LAMA (29.9\%). LAMA/LABA and LAMA were used in $16.3 \%$ and $14.5 \%$ of patients, respectively. Systemic corticosteroids were used in $20.1 \%$ of patients before the AE-COPD event. More patients with ACO were treated with inhaled therapy compared with those manifesting pure COPD. ICS-containing regimens and LABA and oral medications such as systemic corticosteroids and leukotriene receptor antagonists were more likely prescribed for patients diagnosed with ACO. Patients with pure COPD were more likely to undergo LAMA/LABA.

\section{Microbiologic analysis}

Microbiological evaluation revealed the presence of respiratory pathogens in $55.1 \%$ of the patients diagnosed with AECOPD (Table 3). Bacteria were found in $33 \%$, including single bacteria detected in $28.8 \%$ and multiple bacteria in $4.2 \%$. Viruses were found in $33.2 \%$ of cases, including a single virus detected in $30.4 \%$ and multiple viruses in $2.8 \%$. Among them, bacterial and viral coinfections were found in 10.3\% (Figure 1).

Bacteriologic and virologic analyses revealed 15 species of bacteria and 10 species of viruses (Table 4). The most frequently detected bacteria were Pseudomonas aeruginosa

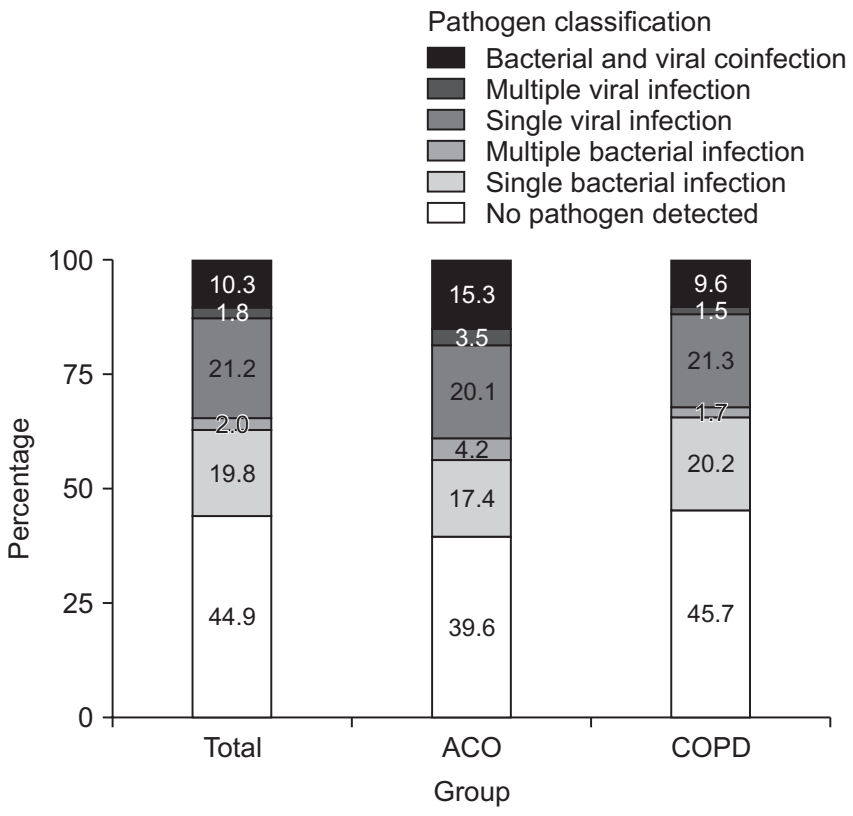

Figure 1. Percentage of respiratory pathogens in patients with acute exacerbation of chronic respiratory disease. Respiratory pathogens were evaluated in total, asthma-COPD overlap (ACO), and chronic obstructive pulmonary disease (COPD) groups.
(9.8\%), followed by Mycoplasma pneumoniae (6.2\%), Streptococcus pneumoniae (5.0\%), and Klebsiella pneumoniae (4.3\%). Influenza A (10.4\%) was the most frequently detected virus, followed by rhinovirus ( $8.7 \%$ ), respiratory syncytial virus (RSV; 3.5\%), and influenza $B(3.3 \%)$.

\section{Discussion}

The present study identified the distribution and pattern of respiratory pathogens in Korean patients diagnosed with AECOPD. The majority of the included patients were classified into group D. Nearly half of the patients used ICS-containing regimens, while $20 \%$ used systemic corticosteroids, which may increase the risk of respiratory infection. Among the total of included patients with AE-COPD, 55.3\% were attributed to infectious pathogens. The most frequently detected bacterium was $P$. aeruginosa, while the most frequently detected virus was influenza $A$, which is consistent with previous reports ${ }^{8,22}$. A higher rate of multiple bacterial infections was found in patients with ACO who were more exposed to inhaled or systemic corticosteroids, experienced prolonged morbidity and had more chronic bronchitis. There was no significant difference in the detected bacterial or viral species between ACO and pure COPD patients, except for $S$. pneumoniae.

Acquisition of newly introduced bacteria is considered one of the major pathogeneses of AE-COPD. Previous studies reported bacterial involvement in AE-COPD, and the most frequently reported bacterial species were Haemophilus influenzae, S. pneumoniae, and Moraxella catarrhalis ${ }^{7}$. Similar results were also reported in an Eastern study ${ }^{8}$. However, our study showed that $H$. influenzae and $M$. catarrhalis are not frequently cultured. $P$. aeruginosa is the major respiratory pathogen detected during AE-COPD. The preponderance of $P$. aeruginosa is presumed to be due to the relatively higher proportion of patients with advanced COPD, use of systemic corticosteroids, and previous hospitalization ${ }^{23,24}$. Similarly, a tertiary hospital in South Korea reported that $P$. aeruginosa is a major respiratory pathogen in AE-COPD ${ }^{25}$. In addition, the epidemiology of infection in South Korea is characterized by gram-negative bacteria, including $P$. aeruginosa, which has been reported relatively high in patients with communityacquired pneumonia ${ }^{26}$. Based on domestic bacterial patterns, $P$. aeruginosa is considered a prevalent causative pathogen when managing moderate-to-severe AE-COPD in South Korea.

Interestingly, multiple bacterial colonies were more identified in ACO patients. In general, fewer bacterial exacerbations have been reported in asthma compared with $\mathrm{COPD}^{27}$. Therefore, less bacterial detection may be expected during acute exacerbation in ACO than in COPD. However, ACO needs to be understood as one of different phenotypes of COPD ${ }^{20}$. Patients with ACO can be classified as a subgroup of COPD 
Table 4. Analysis of bacterial and viral species in patients with acute exacerbation of chronic obstructive pulmonary disease

\begin{tabular}{|c|c|c|c|c|}
\hline & Total $(n=1,186)$ & $\operatorname{ACO}(n=144)$ & $\operatorname{COPD}(n=1,042)$ & p-value \\
\hline \multicolumn{5}{|l|}{ Bacteria } \\
\hline Mycoplasma pneumoniae* & $73(6.2)$ & $9(6.3)$ & $64(6.1)$ & 0.703 \\
\hline Chlamydophila pneumoniae* & $18(1.5)$ & $2(1.4)$ & $16(1.5)$ & 0.970 \\
\hline Legionella pneumophila PCR & $5(0.4)$ & 0 & $5(0.5)$ & 0.815 \\
\hline Bordetella pertussis PCR & $2(0.2)$ & 0 & $2(0.2)$ & $>0.99$ \\
\hline Haemophilus influenzae culture & $22(1.9)$ & $2(1.4)$ & $20(1.9)$ & 0.910 \\
\hline Streptococcus pneumoniae culture & $59(5.0)$ & $14(9.7)$ & $45(4.3)$ & 0.010 \\
\hline Moraxella catarrhalis culture & $10(0.8)$ & $2(1.4)$ & $8(0.8)$ & 0.782 \\
\hline Pseudomonas aeruginosa culture & $116(9.8)$ & $13(9.0)$ & $103(9.9)$ & 0.860 \\
\hline Klebsiella pneumoniae culture & $51(4.3)$ & $5(3.5)$ & $46(4.4)$ & 0.761 \\
\hline Escherichia coli culture & $28(2.4)$ & $7(4.9)$ & $21(2.0)$ & 0.070 \\
\hline MSSA culture & $5(0.4)$ & $1(0.7)$ & $4(0.4)$ & $>0.99$ \\
\hline MRSA culture & $27(2.3)$ & $7(4.9)$ & $20(1.9)$ & 0.055 \\
\hline Haemophilus parainfluenzae culture & 0 & 0 & 0 & - \\
\hline Stenotrophomonas maltophilia culture & $4(0.3)$ & $1(0.7)$ & $3(0.3)$ & 0.983 \\
\hline Group B beta hemolytic Streptococcus culture & $1(0.1)$ & 0 & $1(0.1)$ & $>0.99$ \\
\hline Group A beta hemolytic Streptococcus culture & $2(0.2)$ & 0 & $2(0.2)$ & $>0.99$ \\
\hline \multicolumn{5}{|l|}{ Virus } \\
\hline Rhinovirus PCR & $103(8.7)$ & $14(9.7)$ & $89(8.5)$ & 0.821 \\
\hline Adenovirus PCR & $13(1.1)$ & $1(0.7)$ & $12(1.2)$ & 0.923 \\
\hline Influenza $\mathrm{A}^{\dagger}$ & $124(10.5)$ & $21(14.6)$ & $103(9.9)$ & 0.577 \\
\hline Influenza B ${ }^{\dagger}$ & $39(3.3)$ & $2(1.4)$ & $37(3.6)$ & 0.132 \\
\hline RSV PCR & $42(3.5)$ & $7(4.9)$ & $35(3.4)$ & 0.501 \\
\hline Parainfluenza PCR & $38(3.2)$ & $8(5.6)$ & $30(2.9)$ & 0.163 \\
\hline Coronavirus PCR & $38(3.2)$ & $2(1.4)$ & $36(3.5)$ & 0.265 \\
\hline Metapneumovirus PCR & $36(3)$ & $6(4.2)$ & $30(2.9)$ & 0.570 \\
\hline Enterovirus PCR & $3(0.3)$ & $1(0.7)$ & $2(0.2)$ & 0.560 \\
\hline Bocavirus PCR & $3(0.3)$ & 0 & $3(0.3)$ & $>0.99$ \\
\hline
\end{tabular}

Values are presented as number (\%).

*Bacteria were detected in respiratory specimens via polymerase chain reaction or in serum via immunoglobulin M measurement. 'Virus was detected in respiratory specimen using immunofluorescence assay or polymerase chain reaction.

ACO: asthma-COPD overlap; COPD: chronic obstructive pulmonary disease; PCR: polymerase chain reaction; MSSA: methicillin-sensitive Staphylococcus aureus; MRSA: methicillin-resistant Staphylococcus aureus; RSV: respiratory syncytial virus.

patients who benefits from ICS use. Indeed, exposure to ICS leads to increased airway bacterial burden and pneumonia risk in COPD, although ICS use is paradoxically associated with a lower risk of $\mathrm{AE}-\mathrm{COPD}^{28-30}$. In addition, patients with ACO included in our study had a longer duration of COPD and more chronic bronchitis, both of which were associated with airway bacterial positivity. A longer exposure to or a higher severity of airway inflammation is correlated with a higher bacterial colonization ${ }^{31,32}$.
Respiratory viruses are important infectious pathogens that trigger AE-COPD. AE-COPD caused by respiratory viruses was more severe and associated with prolonged recovery ${ }^{33,34}$. In our study, the prevalence of respiratory viruses was $33.2 \%$ in patients with AE-COPD. In our study, the most commonly detected virus was influenza $A$. Although several studies have reported that rhinovirus is the most frequently detected virus during AE-COPD, it is known that the influenza virus is more common in severe AE-COPD ${ }^{7,35}$. Rhinovirus was the second 
most commonly detected virus in our study. RSV represents an important pathogen in AE-COPD, and accounted for $11.4 \%$ of hospitalizations for $\mathrm{COPD}^{36}$. RSV was the third most commonly detected virus in our study. Further studies are needed to evaluate the mechanism underlying aggravation of airway inflammation by respiratory viruses leading to AE-COPD.

This study has several limitations. First, our observational study was conducted cross-sectionally without evaluating the treatment for AE-COPD and clinical outcomes according to microbiologic patterns. However, it is speculated that our patients received standard treatment for AE-COPD by pulmonologists in university hospitals. Second, considering the high symptom scores and frequent exacerbation histories in our study patients, the proportion of patients without inhaled therapy or pneumococcal vaccination was relatively high. Additional studies are needed to investigate adherence to current guidelines for management of stable COPD. Third, compared with the general COPD population, the study population appeared to use systemic corticosteroids more frequently before an AE-COPD event. Information on the reason for systemic corticosteroid use in patients with COPD was not available.

In conclusion, distinct microbiological patterns were identified in patients with moderate-to-severe AE-COPD at 28 medical centers in South Korea. More than half of AE-COPDs were caused by infectious pathogens with similar rates of bacterial and viral detection. The most frequently detected bacteria and viruses were $P$. aeruginosa and Influenza $A$. Multiple bacterial colonization was more frequently found in ACO compared with pure COPD.

\section{*Author Affiliations}

${ }^{\mathrm{l}}$ Division of Pulmonary and Critical Care Medicine, Department of Internal Medicine, Seoul Metropolitan GovernmentSeoul National University Boramae Medical Center, Seoul National University College of Medicine, Seoul, ${ }^{2}$ Division of Pulmonary, Allergy and Critical Care Medicine, Kangnam Sacred Heart Hospital, Seoul, ${ }^{3}$ Division of Pulmonology and Critical Care Medicine, Department of Internal Medicine, Severance Hospital, Yonsei University College of Medicine, Seoul, ${ }^{4}$ Department of Internal Medicine, School of Medicine, Kyungpook National University Hospital, Daegu, ${ }^{5}$ Department of Internal Medicine, Gachon University Gil Medical Center, Incheon, ${ }^{6}$ Division of Pulmonology, Allergy and Critical Care Medicine, Department of Internal Medicine, Korea University Guro Hospital, Korea University College of Medicine, Seoul, ${ }^{7}$ Division of Pulmonology and Critical Care Medicine, Department of Internal Medicine, Inje University Haeundae Paik Hospital, Inje University College of Medicine, Busan, ${ }^{8}$ Division of Pulmonology, Allergy and Critical Care Medicine, Department of Internal Medicine, Korea University Anam Hospital, Korea University College of Medicine, Seoul, ${ }^{9}$ Division of
Pulmonary, Allergy and Critical Care Medicine, Department of Internal Medicine, Hallym University Chuncheon Sacred Heart Hospital, Hallym University College of Medicine, Chuncheon, ${ }^{10}$ Department of Pulmonary and Critical Care Medicine, Asan Medical Center, University of Ulsan College of Medicine, Seoul, ${ }^{11}$ Department of Internal Medicine, Ulsan University Hospital, University of Ulsan College of Medicine, Ulsan, ${ }^{12}$ Division of Pulmonary and Critical Care Medicine, Hanyang University Guri Hospital, Hanyang University College of Medicine, Guri, ${ }^{13}$ Division of Pulmonary, Allergy, and Critical Care Medicine, Department of Medicine, Hallym University Sacred Heart Hospital, Hallym University College of Medicine, Anyang, ${ }^{14}$ Department of Internal Medicine, Seoul St. Mary's Hospital, College of Medicine, The Catholic University of Korea, Seoul, ${ }^{15}$ Department of Internal Medicine, Uijeongbu St. Mary's Hospital, College of Medicine, The Catholic University of Korea, Seoul, ${ }^{16}$ Bucheon St. Mary's Hospital, College of Medicine, The Catholic University of Korea, Bucheon, ${ }^{17}$ Department of Internal Medicine, Ewha Womans University Seoul Hospital, Ewha Womans University College of Medicine, Seoul, ${ }^{18}$ Division of Pulmonary and Critical Care Medicine, Department of Medicine, Samsung Medical Center, Sungkyunkwan University School of Medicine, Seoul, ${ }^{19}$ Department of Internal Medicine and Environmental Health Center, Kangwon National University College of Medicine, Chuncheon, ${ }^{20}$ Department of Internal Medicine, Dong-A University College of Medicine, Busan, ${ }^{21}$ Division of Pulmonary and Critical Care Medicine, Department of Internal Medicine, Incheon St. Mary's Hospital, College of Medicine, The Catholic University of Korea, Seoul, ${ }^{22}$ Division of Pulmonary and Critical Care Medicine, Department of Internal Medicine, Seoul National University Hospital, Seoul, ${ }^{23}$ Division of Pulmonary and Critical Care Medicine, Department of Internal Medicine, Yeouido St. Mary's Hospital, College of Medicine, The Catholic University of Korea, Seoul, ${ }^{24}$ Division of Pulmonary and Critical Care Medicine, Department of Internal Medicine, Daejeon St. Mary's Hospital, College of Medicine, The Catholic University of Korea, Seoul, ${ }^{25}$ Division of Pulmonary and Critical Care Medicine, Department of Internal Medicine, Dongguk University Ilsan Hospital, Goyang, ${ }^{26}$ Department of Pulmonary and Critical Care Medicine, Ajou University School of Medicine, Suwon, ${ }^{27}$ Department of Internal Medicine, Konkuk University School of Medicine, Seoul, Republic of Korea

\section{Authors' Contributions}

Conceptualization: Lee HW, Yoo KH, Kim DK. Data curation: Lee HW, Sim YS, Jung JY, Seo H, Park JW, Min KH, Lee JH, Kim BK, Lee MG, Oh YM, Ra SW, Kim TH, Hwang YI, Rhee CK, Joo H, Lee EG, Lee JH, Park HY, Kim WJ, Um SJ, Choi JY, Lee CH, An TJ, Park Y, Yoon YS, Park JH, Yoo KH, Kim DK. Formal analysis: Lee HW, Yoo KH, Kim DK. Writing - original 
draft preparation: Lee HW, Yoo KH, Kim DK. Writing - review and editing: Lee HW, Sim YS, Jung JY, Seo H, Park JW, Min KH, Lee JH, Kim BK, Lee MG, Oh YM, Ra SW, Kim TH, Hwang YI, Rhee CK, Joo H, Lee EG, Lee JH, Park HY, Kim WJ, Um SJ, Choi JY, Lee CH, An TJ, Park Y, Yoon YS, Park JH, Yoo KH, Kim DK. Obtained funding: Yoo KH, Kim DK. Study supervision: Yoo KH, Kim DK. Approval of final manuscript: all authors.

\section{Conflicts of Interest}

No potential conflict of interest relevant to this article was reported.

\section{Funding}

This work was supported by Grant No. KATRD-S-2019-1 awarded by the Korean Academy of Tuberculosis and Respiratory Diseases.

\section{References}

1. Lozano R, Naghavi M, Foreman K, Lim S, Shibuya K, Aboyans $\mathrm{V}$, et al. Global and regional mortality from 235 causes of death for 20 age groups in 1990 and 2010: a systematic analysis for the Global Burden of Disease Study 2010. Lancet 2012;380:2095-128.

2. Raherison C, Girodet PO. Epidemiology of COPD. Eur Respir Rev 2009;18:213-21.

3. Park J, Kim HJ, Lee CH, Lee CH, Lee HW. Impact of long-term exposure to ambient air pollution on the incidence of chronic obstructive pulmonary disease: a systematic review and meta-analysis. Environ Res 2021;194:110703.

4. Soler-Cataluna JJ, Martinez-Garcia MA, Roman Sanchez P, Salcedo E, Navarro M, Ochando R. Severe acute exacerbations and mortality in patients with chronic obstructive pulmonary disease. Thorax 2005;60:925-31.

5. Niewoehner DE. The impact of severe exacerbations on quality of life and the clinical course of chronic obstructive pulmonary disease. Am J Med 2006;119(10 Suppl 1):38-45.

6. Sapey E, Stockley RA. COPD exacerbations: 2: aetiology. Tho$\operatorname{rax}$ 2006;61:250-8.

7. Sethi S, Murphy TF. Infection in the pathogenesis and course of chronic obstructive pulmonary disease. N Engl J Med 2008;359:2355-65.

8. Shimizu K, Yoshii Y, Morozumi M, Chiba N, Ubukata K, Uruga $\mathrm{H}$, et al. Pathogens in COPD exacerbations identified by comprehensive real-time PCR plus older methods. Int J Chron Obstruct Pulmon Dis 2015;10:2009-16.

9. Monso E, Ruiz J, Rosell A, Manterola J, Fiz J, Morera J, et al. Bacterial infection in chronic obstructive pulmonary dis- ease: a study of stable and exacerbated outpatients using the protected specimen brush. Am J Respir Crit Care Med 1995; 152(4 Pt 1):1316-20.

10. Rosell A, Monso E, Soler N, Torres F, Angrill J, Riise G, et al. Microbiologic determinants of exacerbation in chronic obstructive pulmonary disease. Arch Intern Med 2005;165:8917.

11. Prieto A, Reyes E, Bernstein ED, Martinez B, Monserrat J, Izquierdo JL, et al. Defective natural killer and phagocytic activities in chronic obstructive pulmonary disease are restored by glycophosphopeptical (inmunoferon). Am J Respir Crit Care Med 2001;163:1578-83.

12. Vermeersch K, Gabrovska M, Aumann J, Demedts IK, Corhay JL, Marchand E, et al. Azithromycin during Acute Chronic Obstructive Pulmonary Disease Exacerbations Requiring Hospitalization (BACE): multicenter, randomized, doubleblind, placebo-controlled trial. Am J Respir Crit Care Med 2019;200:857-68.

13. van Velzen P, Ter Riet G, Bresser P, Baars JJ, van den Berg BT, van den Berg JW, et al. Doxycycline for outpatient-treated acute exacerbations of COPD: a randomised double-blind placebo-controlled trial. Lancet Respir Med 2017;5:492-9.

14. Sethi S, Sethi R, Eschberger K, Lobbins P, Cai X, Grant BJ, et al. Airway bacterial concentrations and exacerbations of chronic obstructive pulmonary disease. Am J Respir Crit Care Med 2007;176:356-61.

15. Groenewegen KH, Wouters EF. Bacterial infections in patients requiring admission for an acute exacerbation of COPD; a 1-year prospective study. Respir Med 2003;97:770-7.

16. Mohan A, Chandra S, Agarwal D, Guleria R, Broor S, Gaur B, et al. Prevalence of viral infection detected by PCR and RTPCR in patients with acute exacerbation of COPD: a systematic review. Respirology 2010;15:536-42.

17. von Elm E, Altman DG, Egger M, Pocock SJ, Gotzsche PC, Vandenbroucke JP, et al. The Strengthening the Reporting of Observational Studies in Epidemiology (STROBE) statement: guidelines for reporting observational studies. Lancet 2007;370:1453-7.

18. Global Initiative for Chronic Obstructive Lung Disease. Global strategy for the diagnosis, management, and prevention of chronic obstructive pulmonary disease, 2020 report [Internet]. Global Initiative for Chronic Obstructive Lung Disease; 2020 [cited 2020 Nov 4]. Available from: https://goldcopd.org/ wp-content/uploads/2019/12/GOLD-2020-FINAL-ver1.203Dec19_WMV.pdf.

19. Lim JU, Kim DK, Lee MG, Hwang YI, Shin KC, In KH, et al. Clinical characteristics and changes of clinical features in patients with asthma-COPD overlap in Korea according to different diagnostic criteria. Tuberc Respir Dis 2020;83(Suppl 1):S34-S45.

20. Jung JY. Characteristics of Asthma-COPD Overlap According to Various Criteria. Tuberc Respir Dis 2021;84:87-8.

21. Yanagisawa S, Ichinose M. Definition and diagnosis of asth- 
ma-COPD overlap (ACO). Allergol Int 2018;67:172-8.

22. Boixeda R, Rabella N, Sauca G, Delgado M, Martinez-Costa X, Mauri M, et al. Microbiological study of patients hospitalized for acute exacerbation of chronic obstructive pulmonary disease (AE-COPD) and the usefulness of analytical and clinical parameters in its identification (VIRAE study). Int J Chron Obstruct Pulmon Dis 2012;7:327-35.

23. Eklof J, Sorensen R, Ingebrigtsen TS, Sivapalan P, Achir I, Boel $\mathrm{JB}$, et al. Pseudomonas aeruginosa and risk of death and exacerbations in patients with chronic obstructive pulmonary disease: an observational cohort study of 22053 patients. Clin Microbiol Infect 2020;26:227-34.

24. Garcia-Vidal C, Almagro P, Romani V, Rodriguez-Carballeira M, Cuchi E, Canales L, et al. Pseudomonas aeruginosa in patients hospitalised for COPD exacerbation: a prospective study. Eur Respir J 2009;34:1072-8.

25. Choi J, Oh JY, Lee YS, Hur GY, Lee SY, Shim JJ, et al. Bacterial and viral identification rate in acute exacerbation of chronic obstructive pulmonary disease in Korea. Yonsei Med J 2019; 60:216-22.

26. Lee MS, Oh JY, Kang CI, Kim ES, Park S, Rhee CK, et al. Guideline for antibiotic use in adults with community-acquired pneumonia. Infect Chemother 2018;50:160-98.

27. Pauwels RA. Similarities and differences in asthma and chronic obstructive pulmonary disease exacerbations. Proc Am Thorac Soc 2004;1:73-6.

28. Contoli M, Pauletti A, Rossi MR, Spanevello A, Casolari P, Marcellini A, et al. Long-term effects of inhaled corticosteroids on sputum bacterial and viral loads in COPD. Eur Respir J 2017;50:1700451.

29. Martinez-Garcia MA, Faner R, Oscullo G, de la Rosa D, Soler-
Cataluna JJ, Ballester M, et al. Inhaled steroids, circulating eosinophils, chronic airway infection, and pneumonia risk in chronic obstructive pulmonary disease: a network analysis. Am J Respir Crit Care Med 2020;201:1078-85.

30. Lee HW, Park J, Jo J, Jang EJ, Lee CH. Comparisons of exacerbations and mortality among regular inhaled therapies for patients with stable chronic obstructive pulmonary disease: Systematic review and Bayesian network meta-analysis. PLoS Med 2019;16:e1002958.

31. Sethi S, Maloney J, Grove L, Wrona C, Berenson CS. Airway inflammation and bronchial bacterial colonization in chronic obstructive pulmonary disease. Am J Respir Crit Care Med 2006;173:991-8.

32. Hill AT, Campbell EJ, Hill SL, Bayley DL, Stockley RA. Association between airway bacterial load and markers of airway inflammation in patients with stable chronic bronchitis. Am J Med 2000;109:288-95.

33. Hurst JR, Donaldson GC, Wilkinson TM, Perera WR, Wedzicha JA. Epidemiological relationships between the common cold and exacerbation frequency in COPD. Eur Respir J 2005; 26:846-52.

34. Seemungal TA, Harper-Owen R, Bhowmik A, Jeffries DJ, Wedzicha JA. Detection of rhinovirus in induced sputum at exacerbation of chronic obstructive pulmonary disease. Eur Respir J 2000;16:677-83.

35. Wu X, Chen D, Gu X, Su X, Song Y, Shi Y. Prevalence and risk of viral infection in patients with acute exacerbation of chronic obstructive pulmonary disease: a meta-analysis. Mol Biol Rep 2014;41:4743-51.

36. Falsey AR. Respiratory syncytial virus infection in elderly and high-risk adults. Exp Lung Res 2005;31 Suppl 1:77. 